\title{
MUSEPICK: AN INTEGRATED TECHNOLOGICAL FRAMEWORK TO PRESENT THE COMPLEX OF SANTISSIMA ANNUNZIATA IN ASCOLI PICENO (ITALY)
}

\author{
E. Petrucci ${ }^{\text {a }}$, D. Rossi ${ }^{\text {a }}$ \\ ${ }^{a}$ UNICAM, School of Architecture and Design, Ascoli Piceno, Italy \\ (enrica.petrucci, daniele.rossi)@unicam.it
}

\begin{abstract}
KEY WORDS: Digital Cultural Heritage, Virtual Reality, Web Platform, Beacon, Micro-location, $360^{\circ}$ Panoramic Image, Immersive
\end{abstract} Walkthrough, 3D model

\begin{abstract}
:
Nowadays, digital media play a central role in a shift towards updated modes of communicating knowledge. In addition to this, the tragic recent events related to the long series of earthquakes that have taken place in central Italy have also, unfortunately, reiterated the need to document and preserve not only the material value of the architectural heritage but also the intangible values related to the events and people that have characterized their history. In this framework, the paper investigates some of the opportunities offered by technological innovations, in particular, by the specific application areas of augmented reality and augmented virtuality. The case study The historical site chosen as case study is the complex of Santissima Annunziata, which has played a very important role in the city of Ascoli Piceno (Italy) for centuries.

The objective was to develop a low-cost web-based platform to serve as a place to gather cultural content related to the diffuse cultural heritage, organized in applications regarding graphical and 3D models as well as $360^{\circ}$ images and archival documents.
\end{abstract}

\section{INTRODUCTION}

Nowadays, digital media play a central role in the shift towards updated modes of communicating knowledge. The language from emerging technologies for cultural heritage tends to emphasize our understanding through sensory perception, defining communication activities that aim to ease understanding, clarify complex aspects, and make the information more explicit and usable. Communication is essentially made with the users' objectives in mind.

In addition, the recent tragic events related to the long series of earthquakes in central Italy have also, unfortunately, reiterated the need to document and preserve not only the material value of the architectural heritage but also the intangible values related to the people and events that have characterized its history.

In this framework, new research areas are growing in importance. In particular, three-dimensionality and virtuality are the key characteristics of this new trend. Such distinctive elements aim to re-establish synergy between cognitive and emotional aspects through approaches that consider users' habits and mental models, creating systems that are ever "closer" and easier to use. Appreciation of the cultural heritage is increasingly focused on the relationship between new technologies and forms of learning/entertainment. In other words, it takes an approach between "amusement" and "edutainment" through which entertainment and fun are used to educate and learn.

Starting from these premises, this contribution investigates some of the opportunities offered by technological innovations, in particular, applications that favour an articulated, profitable combination of real and virtual, or rather, the specific application areas of augmented reality and augmented virtuality.

The experimentation addresses the complex of Santissima Annunziata in Ascoli Piceno, one of the most complex, stratified buildings in the city (Fig.1-3). For this reason, some opportunities offered by technological innovations were investigated, focusing in particular on applications that favour the organized, fruitful fusion of real and virtual environments. In the case at hand, as with the relics of most cultural goods, the content transmitted through the applications is very heterogeneous: documentary sources, archival resources, graphical models, images of the current state or those showing the evolution of the complex over time. In this sense, the applications are presented as new "cultural opportunities" through which heritage conservation does not end with material conservation, but rather is realized by offering particular technological applications that can activate new ways of visualizing and interpreting archival/documentary data for their active enhancement.

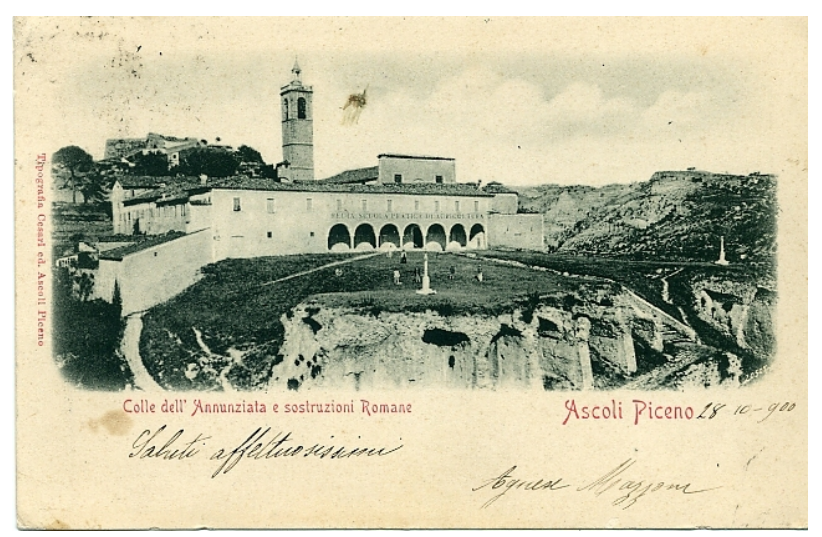

Figure 1. Postcard depicting the Annunziata complex in the early 1900 s

In the applications proposed, the methodological approach entails a series of investigative phases, starting with recovering and cataloguing, and then organizing and digitalizing the data. The organization forms the basis to subsequently build the interrelationships with a web-based platform, guaranteeing rigorous quality control and trustworthiness of the original data and the content produced throughout the development.

Already beginning in the mid-1960s, a new social function was attributed to cultural goods, which were considered a set "of goods that constitute material testimony with civil value". This definition represents a very important conceptual evolution in which the aesthetic concept of the "beauty of art" was overcome in favour of the concept of historicity. In relation to these new 
concepts, which affect the category of cultural goods, the concept of enhancement as a set of actions aimed at wide, diversified use by the community is also expanded. From that moment on, enhancement of the cultural heritage has increasingly centred on the relationship between new technologies and forms of learning/entertainment, arriving at the above-mentioned approach of "amusement" or "edutainment", through which education and learning occur while being entertained and having fun. The means and opportunities of doing so have progressively increased, allowing users to exercise their right to information and enjoyment of the cultural good.

Digital mediation techniques, the preparation of data platforms, and the practices of simulation, animation and three-dimensional reconstruction have redefined space and time in both the transmission and use of knowledge. In fact, it is clear that today, new media forms play a central role in a "displacement" towards new models of communication that aim at expanding the cultural offer with increasingly rapid and immediate forms. Communicational actions aim to ease understanding, clarify complex aspects, present concepts clearly and synthetically, and make the information explicit and usable while maintaining a high level of science in the proposed content.

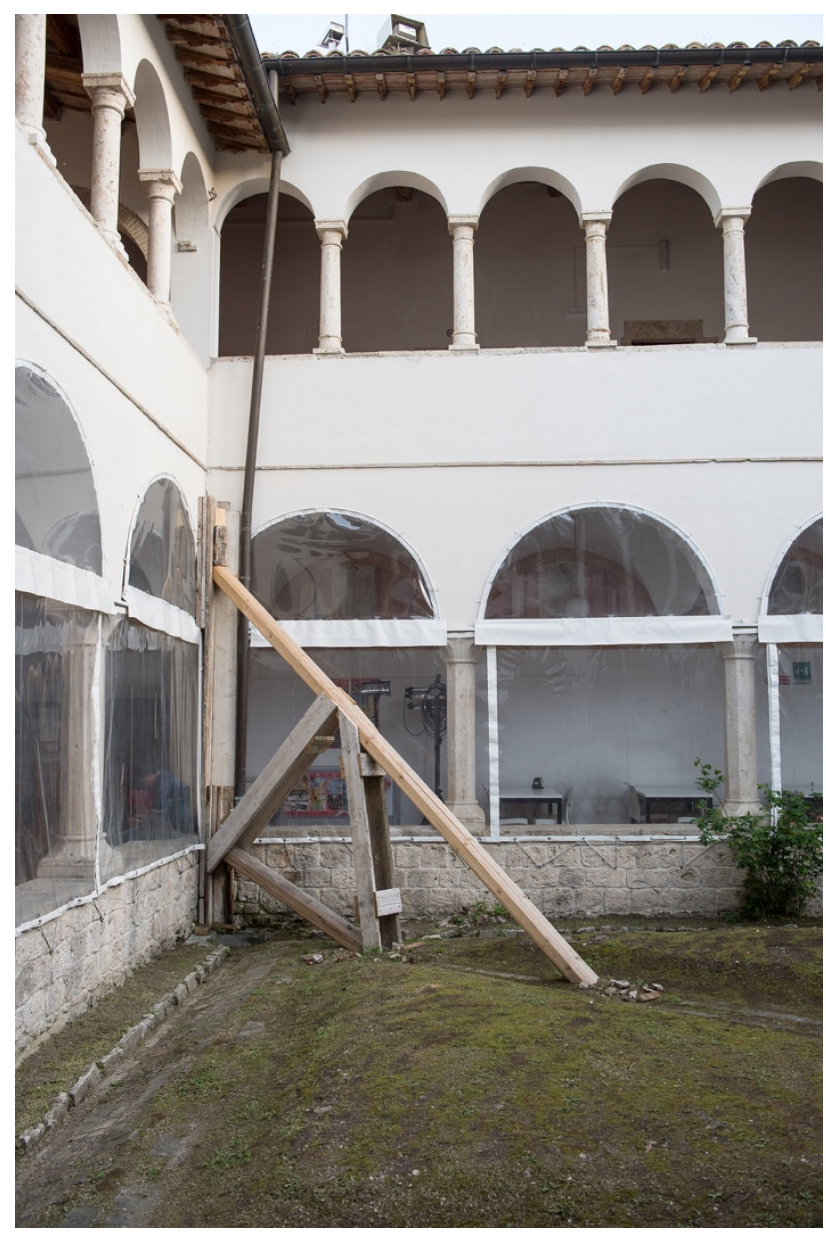

Figure 2. Emergency action for the safety of the main cloister after the earthquakes of August 2016

\section{CASE STUDY}

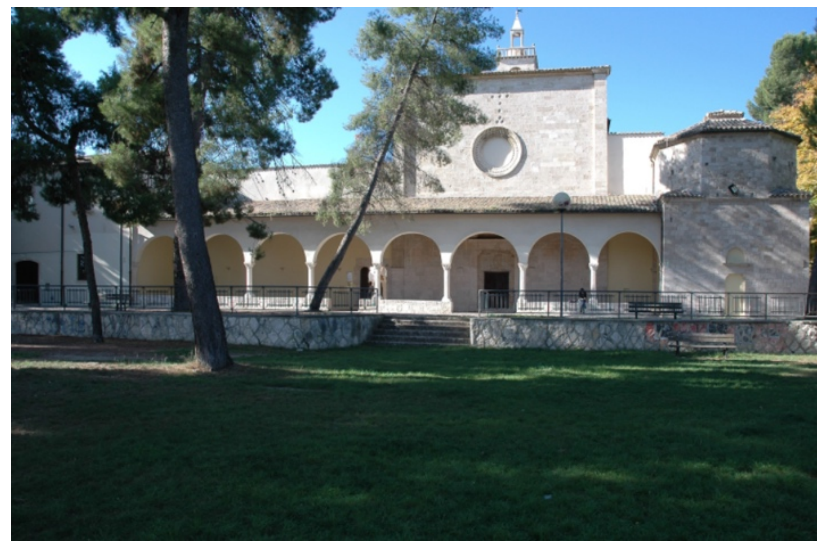

Figure 3. Main entrance of the Annunziata complex

The site chosen is the complex of Santissima Annunziata, which has played a very important role in the city for centuries. Today, it is neither included in the tourist circuit of the city nor wellknown to the local population. The monastery was created as a hospital, but its use has changed over the centuries; today it houses the School of Architecture and Design at the University of Camerino. The complex includes the church and the monastery building with two cloisters. The smaller cloister dates to the fourteenth century and the larger dates to the fifteenth century, when the current church was built. The complex holds values that have become stratified over the centuries. To simplify and make the monument more understandable, thirteen development phases were identified. To determine the phases, the authors carried out in-depth historical research by studying iconographic, archival, and documentary sources in addition to directly reading the geometrical, material, and artistic data.

- Phase 1 date to the Roman era, as attested by archaeological remains in the area (Fig.4);

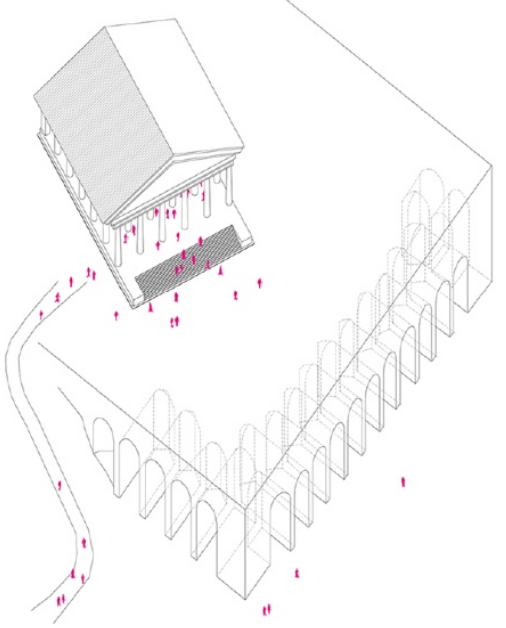

Figure 4. Phase 1

- Phase 2 covers 1000-1199, and the eleventh century in particular, when a hospital called Santissima Annunziata was established to welcome wayfarers (Fig.5); 


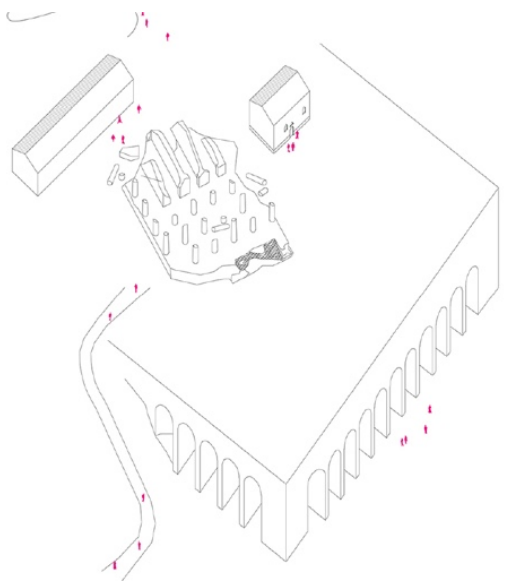

Figure 5. Phase 2

- Phase 3 covers 1200-1486. Between the thirteenth and fourteenth centuries, the convent was expanded with the creation of a cloister and church. The layout of the environments followed the canonical structure of the mendicant orders: no higher than one floor, with a refectory, dormitories, and services in the underground rooms;

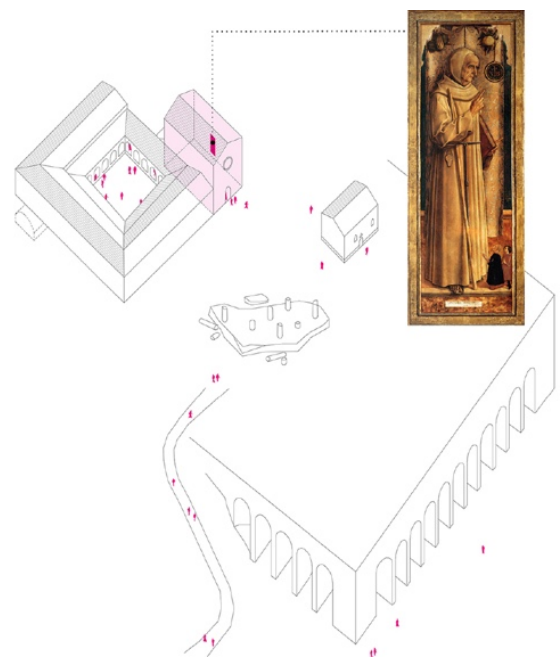

Figure 6. Phase 3

- $\quad$ Phase 4 corresponds to 1494-1514. At the beginning of the sixteenth centuries, the Friars Minor expanded the monastery, raising and lengthening the existing spaces. In the middle of the sixteenth century, the

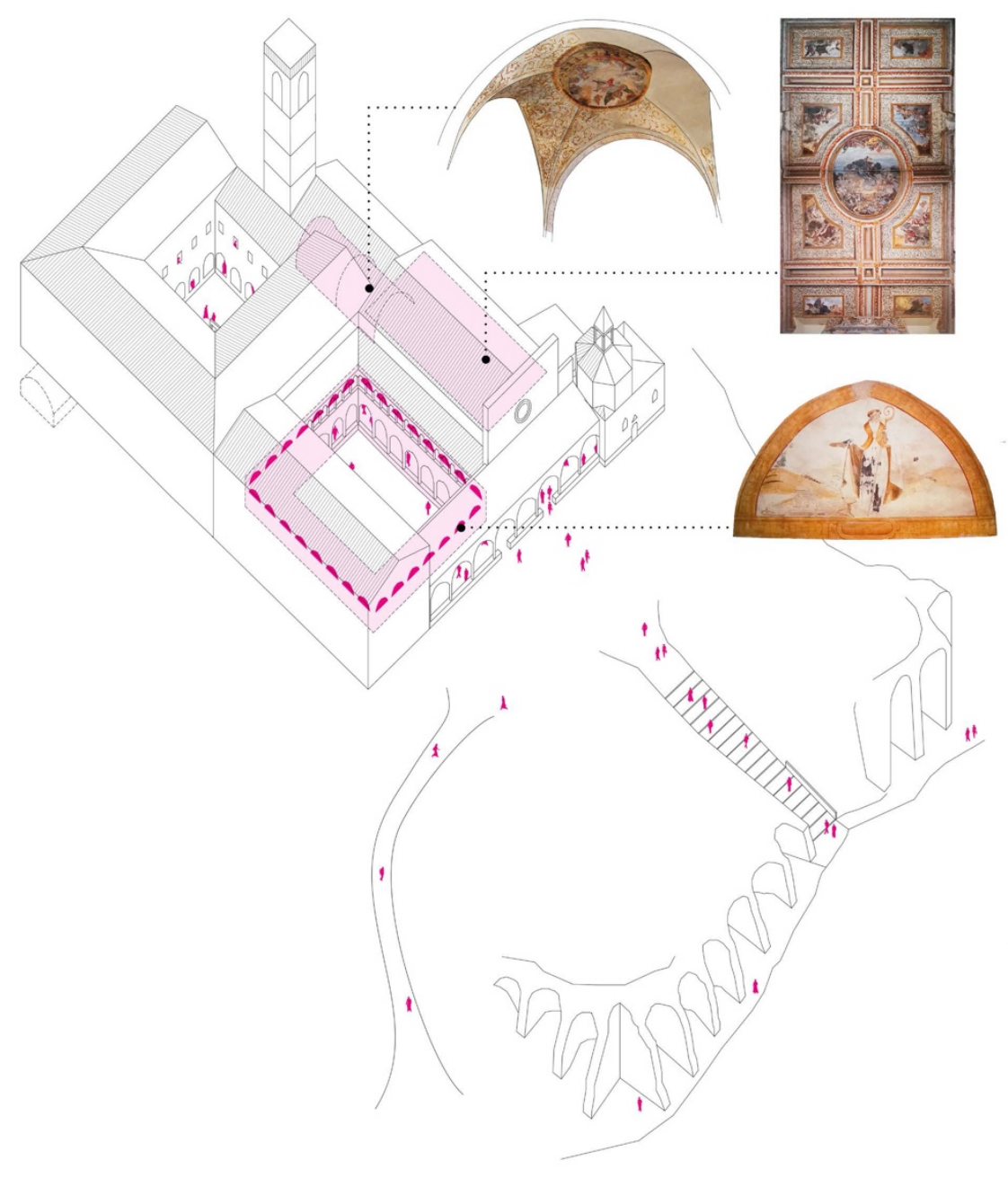

Figure 7. Phase 4 and phase 5 
campanile was finished, along with the eastern cloister and the portico in front of the convent façade. In 1519 Cola dell'Amatrice finished the fresco depicting $L$ 'Andata al Calvario for the large refectory (Fig.7);

- Phase 5 corresponds to the seventeenth century, the beginning of which saw the construction of the second order in the eastern cloister. In 1642 the lunettes of the lower portico were decorated and 1699 saw the decoration of the church ceiling and the apse vaults. To cover the costs, the monks asked for help from Pope Clement X, who, in 1674, bestowed plenary indulgence on those who visited the convent from vespers to sunset on 25 March every year (Fig.7);

- Phase 6 encompasses the eighteenth century, when the monastery of Friars Minor became the site for the study of Sacred and Profane Sciences and Sacred Theology and was further expanded. Between 1724 and 1797 the portico was raised, stalls and storerooms were added in the north, and a loggia was built in the western cloister;

- $\quad$ Phase 7 coincides with the period from 1800 to 1862 . At the beginning of the nineteenth century, Napoleon Bonaparte's French soldiers occupied the complex, which temporarily became a military barracks. In 1861, with the suppression of the religious orders, the complex became property of the state and the structure began to slowly decline. Some works were placed in the safety of the nearby Municipal Art Gallery of Ascoli Piceno, while others were stolen or lost;

- Phase 8, covering 1862-1921, relates to the transformation of the complex after Italian unification in order to house the Regina Margherita Conservatory. In 1872 it was ceded to the City of Ascoli, which established a girls' orphanage and in 1881 it became the Royal School of Agriculture;

- During Phase 9, which lasted from 1921 to 1946, the Parco della Rimembranza was created in memory of those who fell in World War I, along with the long stairway that connected the complex to the city centre. The structure was restored in 1929 (Fig.8);

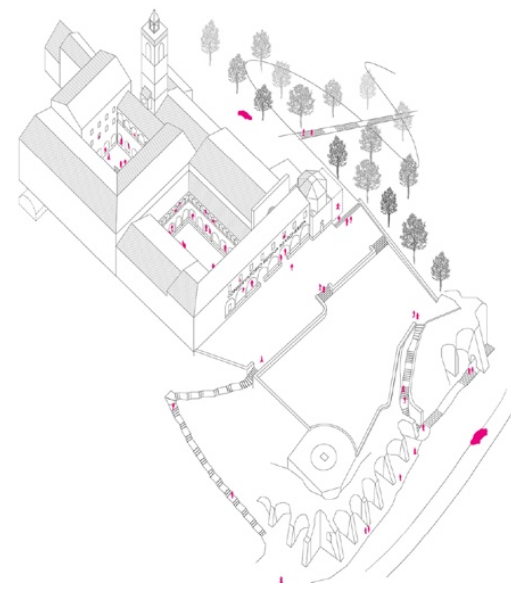

Figure 8. Phase 9

- Phase 10 spans 1946-1952. In 1946, an earthquake damaged the monastery and it was necessary to demolish the second floor of the portico in front of the façade. In 1948 the portico arcades were closed for static aims;

- In phase 11, which lasted from 1952 to 1972, different restoration works were undertaken, including repairs to the campanile and chapel roofs. In 1972 the structure was definitively closed following a strong earthquake and remained unused for many years;

- Between 1985 and 1993 (phase 12), significant restoration and consolidation work was done.

- In 1996 (phase 13) the City of Ascoli Piceno ceded the monastery to the University of Camerino to house the School of Architecture, which is still located in the complex (Fig.9).

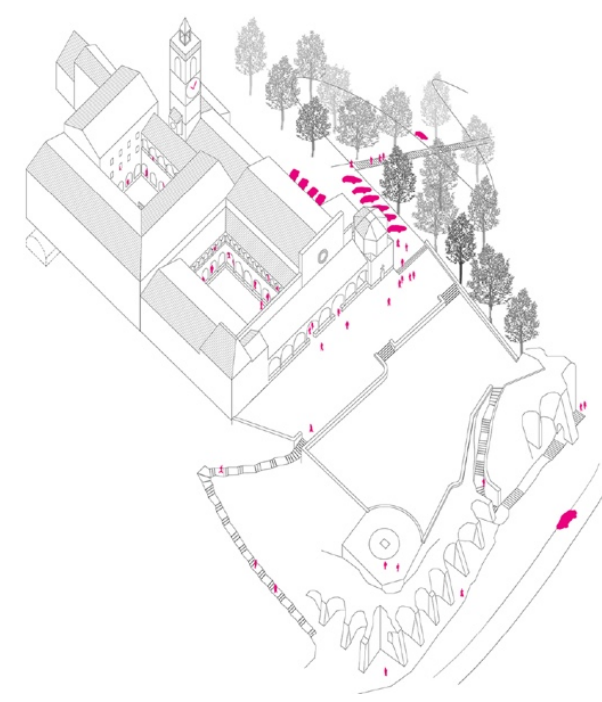

Figure 9. Phase 13

\section{APPLICATIONS}

There are a large number of buildings and monuments in Italy with high social and cultural value. In virtue of this widespread heritage, enhancing the quality of these buildings with specific interventions seems to represent an unsustainable effort by local administrations in small/medium communities.

The solution adopted in our experimentation is inspired by the idea of the diffuse museum, intended as a territory enhanced by the diffuse quality of its building fabric rather than by single monuments. Just as any traditional museum is now equipped with a web infrastructure and a series of applications to ease its use, a diffuse museum should likewise use tools and a technological container to organize all of its cultural objects.

For this reason, there is clearly a need to define a technological and operational framework on which a series of standardized digital applications can be created.

The objective was to develop a low-cost platform that could be personalized based on the content, easily used, and which could interact with other devices (smartphones, tablets, head-mounted displays, etc.).

Analyzing the array of current technologies, the communication strategy is divided into two levels.

The first allows visitors to discover the complex before a visit, while the second enhances the on-site visit, using innovative, easily accessible technologies. Statistical projections indicate an exponential increase in the use of the Internet with the spread of smartphones and tablets, and an evolution in new virtual-reality technologies. Technologies based on augmented reality can therefore provide added information to improve a visit to a building, while virtual reality can be used for special events or to promote a specific work, involving visitors even before their onsite tour. 

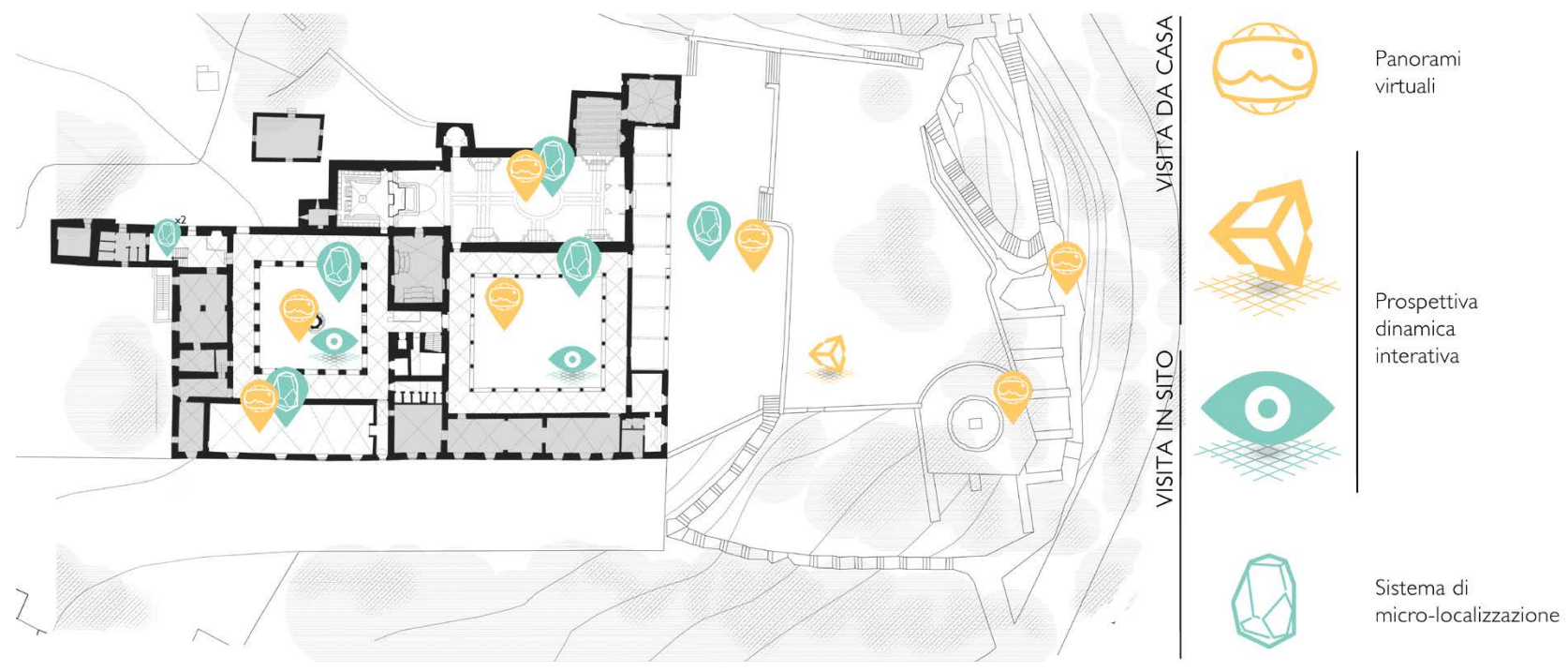

Figure 10. Location of the applications in the Annunziata complex

\subsection{Web Platform}

The first phase in creating the communication project was to develop a web platform, which, supported by other technological apparatus, involves visitors in discovering the Annunziata complex, both at home via the Internet and on site with other technologies connected to the Internet. The platform was designed starting from the concept (the mock-up), its structure (the site map), and design planning, using simple stylized graphics for the portal for easy use by different types of users. The platform is called "Musepick". The idea communicated by the name itself is the search for an experience in discovering architectural goods and works of art with a high cultural value. Today, thanks to the spread of smartphones and tablets equipped with web browsers that can support HTML5 and CSS3, the market of app development has moved towards so-called webapps. Webapps are easily assimilated and responsive websites. That is, with a graphical layout adaptable to different devices and used from a smartphone, they appear entirely like applications for mobile operating systems (Android, iOS, etc.). Developing a webapp means developing a mobile tool that can be reconfigured based on the user's device. Desktops, laptops, tablets, or smartphones of any brand and model can best visualize the information present within. Once the choice is made, an opensource content-management system (CMS) is identified that respects these characteristics. The choice was made to use Wordpress, which is based on PHP and MySql.
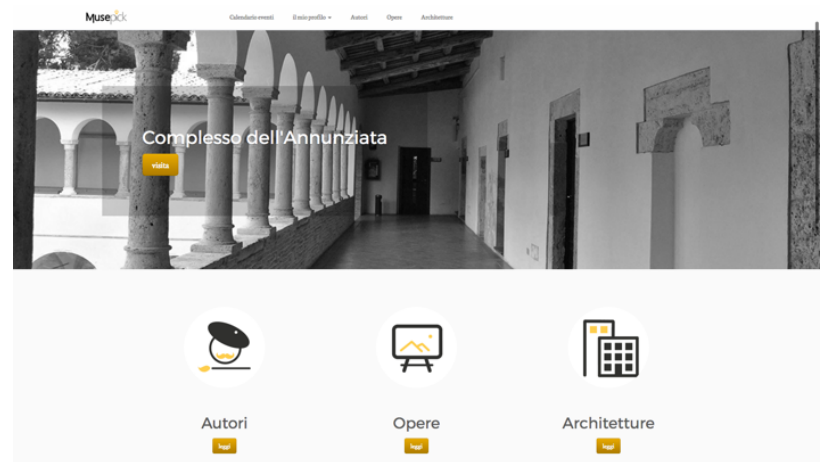

Figure 11. Home page of the web portal
To share the restoration story of the building, a series of reconstructive models were designed to correspond to the transformation phases marking the evolution of the complex. The architecture was represented in monometric axonometric projection. These models were positioned towards the front because they are very explanatory and each image was therefore enriched with a brief description of the contents.

In the section of the website related to the building tour, three different technologies were experimented with to communicate information related to the case study not passively, but following interactive, immersive means. Two of these were made available for an online visit. One uses virtual panoramas for a photographic visualization of the places and the other offers an immersive visit of the 3D models of the different construction phases of the complex. The third technology, instead, allows the on-site visit to be improved by means of devices that track the user's movements within the real environment (Fig.11).

\section{$3.2360^{\circ}$ panorama}

To allow the tour to begin at home, or to investigate what was already seen, the use of panoramic photos was experimented with.

This was inspired by the ancient invention of panoramas, large structures that displayed paintings on circular canvases to be observed from the centre. After walking through dark corridors, viewers found themselves immersed within an exciting $360^{\circ}$ scene. Today, the best way to take visitors inside the current building is by visualizing virtual panoramas or spherical photos, $360^{\circ}$ panoramic images reconstructed by composing specific photos with photo-stitching programs. With this technique, one can obtain a real virtual tour of the Annunziata complex. Seven different tours allow visitors to enter key parts of the building that are not always accessible, for example, the Annunziata church. With a few simple steps, the software used to mosaic photographic images returns a photo sphere, which can be used with a smartphone's gyroscope in a language that allows visualization through the CMS (Wordpress) and the device. For our experimentation, free Google software was used. Once the photo sphere is loaded, it returns an iframe code to copy within the webpage (Fig.12). 

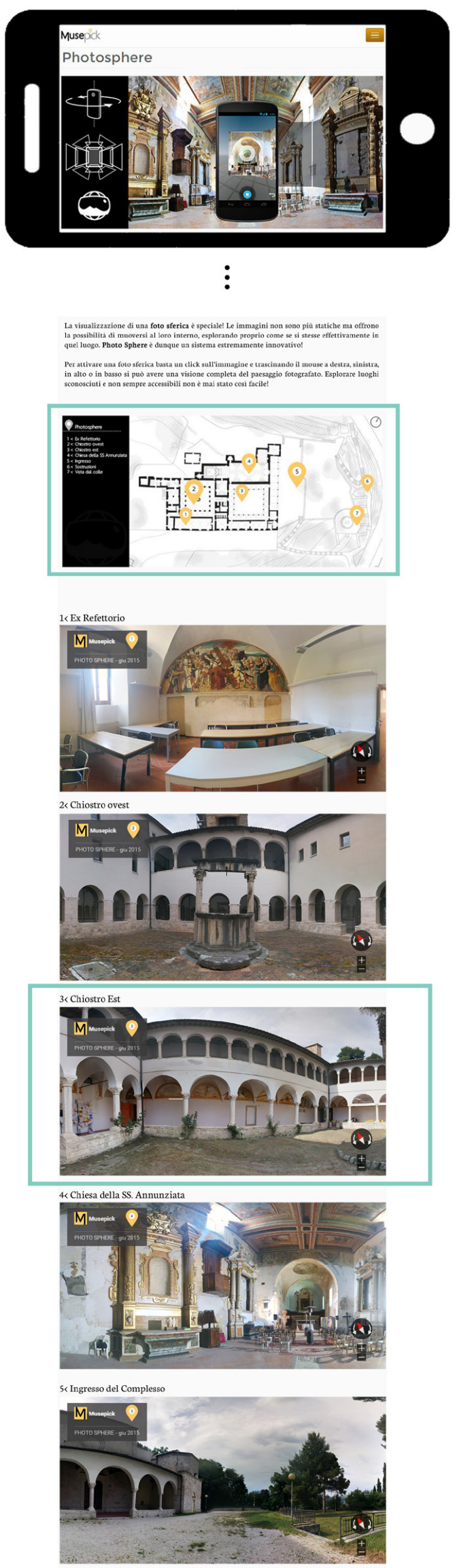

Figure $12.360^{\circ}$ panoramic images used in the web-portal

\subsection{Immersive Walkthrough}

Another strategy to promote the building was developed through the interactive dynamic-perspective technologies often used for simulations and video games but which can also be applied to architectural visualizations. The interactive dynamic perspective is not a classical perspective, but rather offers infinite points of view that can be chosen by the visitor. Within the perspective, the view follows the user's movements and the visible environment is the fruit of graphical design. Through this system, it is therefore possible to visit the Annunziata complex visualizing not only its current state, but also and especially what no longer exists and which can be recreated in the virtual environment. Six 3D models were created to synthesize the thirteen historical phases. The visitor can navigate through the various eras, moving from one historical period to another, from walking visualizations to in-flight (drone) visualizations.

Architectural representation is based on the use of simplified volumes to enhance their characteristics, in the same way as a scale model. From the ground, visitors can always visualize the layout in order to best orient themselves within the current complex. An audio guide that describes the main historical events adds additional information to the visit.

An additional step in this case study is the use of gaming technologies for cultural aims, making use of an oculus rift visor. Through the dynamic interactive perspective, the visitor, wearing the visor and using a joystick, can decide where to move and what to explore and thus become completely immersed in the environment.

The 3D models were processed and prepared for real-time navigation using Unity 3D and were exported in HTML format in order to be visualized on the most common web browsers.

In the project, 12 scenes were created, two for each phase in the history of the complex. These allow the 3D space to be navigated from two perspectives: on foot, with the cameras at average human height, and in a drone mode, flying $50 \mathrm{~m}$ above the ground.

Moving through the different environments, yellow "pick" markers are found - a symbol of the Musepick website- which actives a specialized 3D audio source that tells about the events related to that historical phase (Fig.13-15).

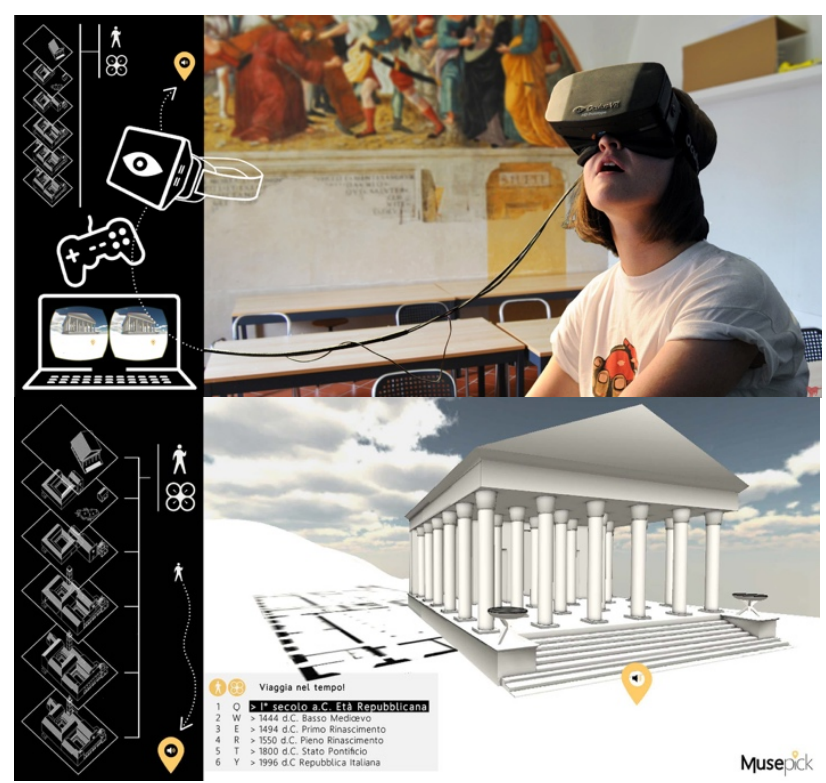

Figure 13. The head mounted display, Oculus Rift beta2, used for the experimentations (above) and the 3D model of the phase 1 (bottom) 

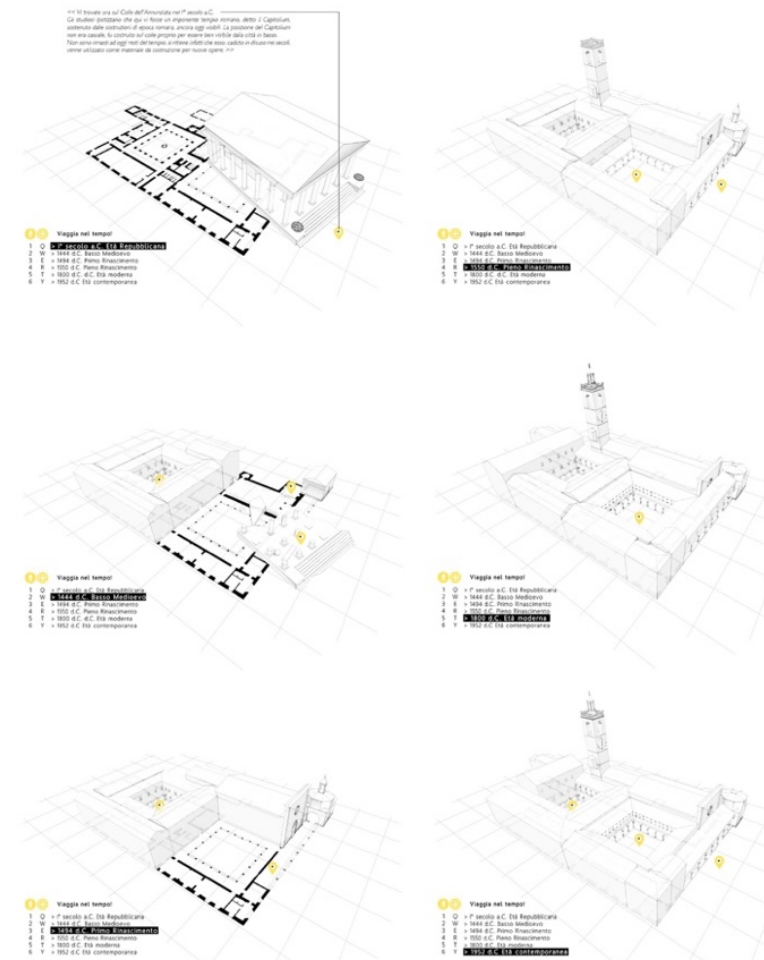

Figure 14. All 3D models used for the immersive walkthrough
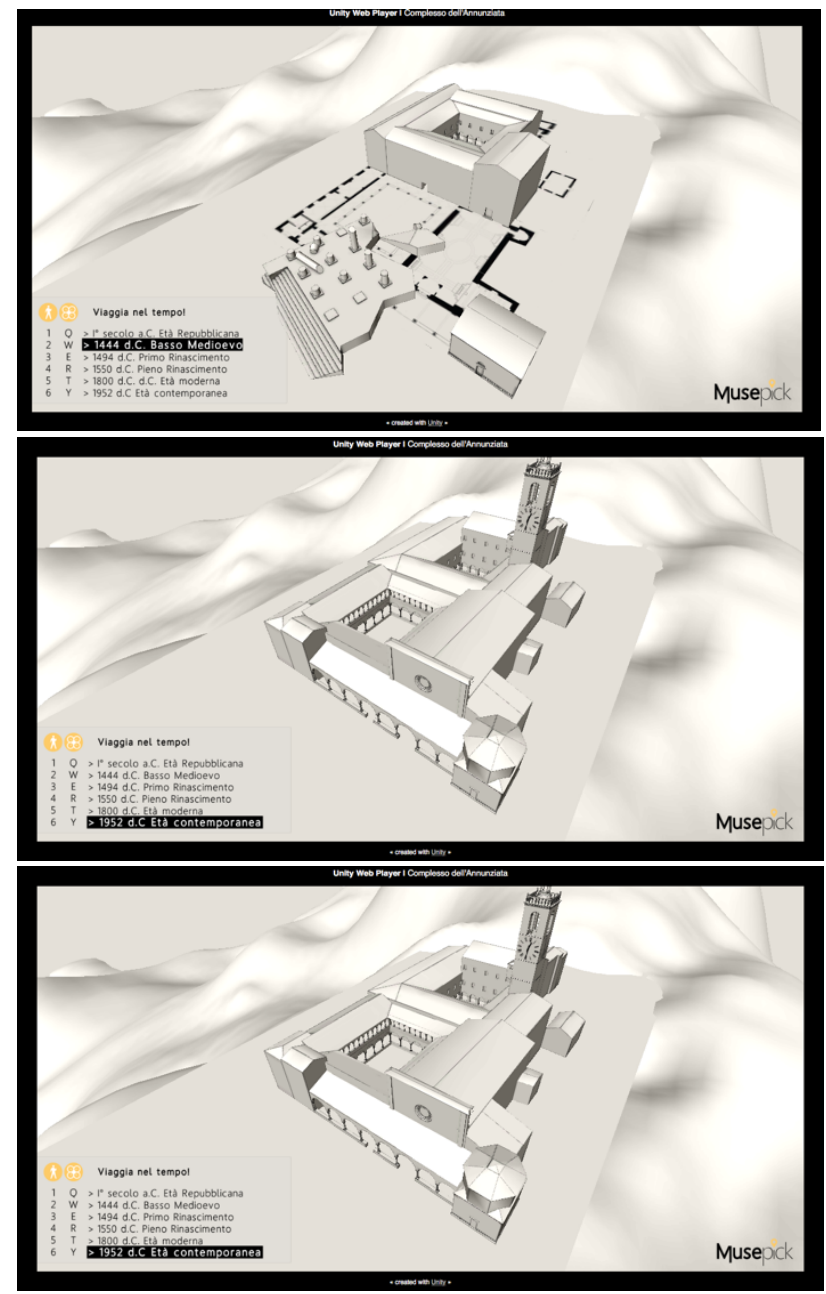

Figure 15. Interface of the immersive walkthrough application elaborated with Unity 3D render engine

\subsection{Mirco-Location}

To complete the communication strategy, a means of visiting from different sites was designed to invite users to discover the hidden beauty of the building.

Beacons are small battery-powered devices that transmit small amounts of data a short distance $(\max .70 \mathrm{~m}$ ) every second. Their technology is based on Bluetooth low energy, which allows data to be sent and received with low energy consumption. A beacon is like a lighthouse. It signals and highlights hidden particulars about the building positioned within real environments. While the visitor moves freely within the structure, information is sent directly to the user's device when the user approaches a certain point.

Among the advantages of this type of technology, beacons allow the works of art to be made active because they then look for the user and not vice versa; they are very small objects and can be easily positioned at any point. A scan like with a QR code is not necessary. They interact directly with the user's device, thereby avoiding the purchase and management of audio guides. Updating the audio-visual content is also very easy because it is managed directly online. Specific locations were tested in our case study to highlight some significant events that are particularly important for the complex. Among these, a beacon was positioned near the important fresco L'Andata al Calvario, by the architect-painter Cola dell'Amatrice. The application allows for in-depth knowledge of the history and techniques of the fresco and also decodes the complex symbolic references that the painter uses for the representation. It is also possible to identify the various restorations of the work (Fig.16).
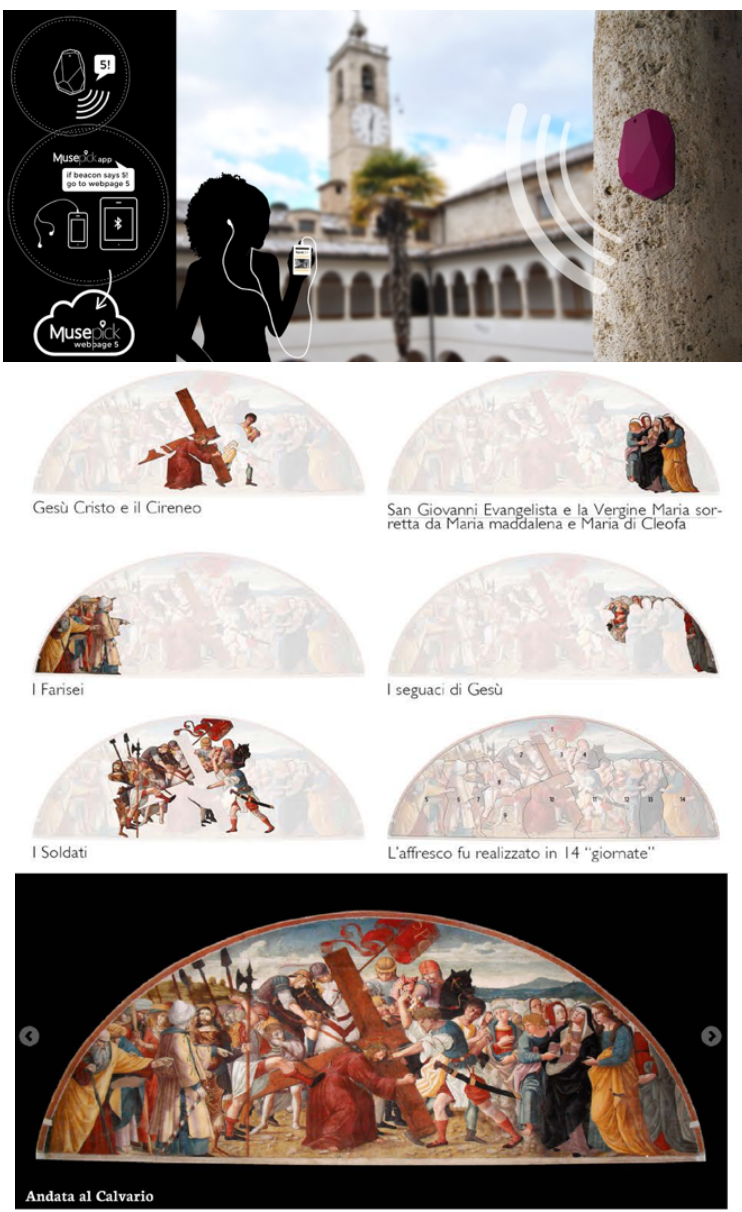

Figure 16. Beacon applications to illustrate the fresco L'Andata al Calvario, by the architect-painter Cola dell'Amatrice 


\section{CONCLUSION}

The present contribution reflected on the value of visual communication in contribution to the area of cultural goods, illustrating a specific experience regarding the case study of the Annunziata complex in Ascoli Piceno. Applications were tested in which the common denominator is the conviction that communication represents an important tool both to enhance and protect the heritage, especially in catastrophic events such as earthquakes, in which the material consistency of the good may be lost.

The innovative digital tools used in this case make an important contribution to memory, in proposing that which no longer exists, but they also serve as a tool to allow for understanding of the history of events that have occurred over time and which have led to the current architectural configuration.

Operationally, the experimentation regarded a web-based platform to serve as a place to gather cultural content related to the diffuse cultural heritage, organized in applications regarding graphical and 3D models as well as $360^{\circ}$ images and archival documents.

In conclusion, it is clear that the specifics of this case allow for the coordinated experimentation of different technologies to make the monument understandable, communicating content according to various levels of depth, which can be used by different types of users.

\section{ACKNOWLEDGEMENTS}

The author would like to thank for their enthusiastic and competent collaboration: Lucia Amatori and Francesca Marcozzi, Master's graduates, School of Architecture and Design, University of Camerino, Ascoli Piceno, Italy;

\section{REFERENCES}

Addison, A. C. (2001). Virtual heritage: technology in the service of culture. In Proceedings of the 2001 conference on Virtual reality, archeology, and cultural heritage (pp. 343-354). ACM.

Mitasova, H., Mitas, L., Ratti, C., Ishii, H., Alonso, J., \& Harmon, R. S. (2006). Real-time landscape model interaction using a tangible geospatial modeling environment. Computer Graphics and Applications, 26(4), 55-63. IEEE.

Pantano, E., \& Tavernise, A. (2009). Learning cultural heritage through information and communication technologies: a case study. Learning culture and language through ICTs: Methods for enhanced instruction, 103-119. IGI Global.

Borghini, S., \& Carlani, R. (2011). La restituzione virtuale dell'architettura antica come strumento di ricerca e comunicazione dei beni culturali: ricerca estetica e gestione delle fonti. Disegnarecon, 4(8), 71-79.

Cervellini, F. \& Rossi D. (2011). Comunicare emozionando. L'edutainment per la comunicazione intorno al patrimonio culturale. Disegnarecon, 4(8).

Boyer, D., \& Marcus, J. (2011). Implementing Mobile Augmented Reality Applications for Cultural Institutions, in Proceedings of Museums and the Web. Toronto: Archives \& Museum Informatics.
Ippoliti, E., Meschini, A., Moscati, A., \& Rossi, D. (2012). Interfacce e tecnologie visual 3D per conoscere, condividere e valorizzare il patrimonio culturale. Disegnarecon, 5(10), 45-54.

Salvo S. (2012). Il convento della SS. Annunziata di Ascoli Piceno, D'Auria, Ascoli Piceno.

Ippoliti E., (edited by) (2013), Valorizzare il Patrimonio Culturale. Esperienze per Ascoli Piceno - Shedding light on the Cultural Heritage. The Ascoli Piceno experience, Aracne Editrice, Roma.

Antinucci, F. (2014). Comunicare nel museo. Gius. Laterza \& Figli Spa.

Ippolito, A., \& Cigola, M. (Eds.). (2016). Handbook of research on emerging technologies for digital preservation and information modeling. IGI Global.

Brusaporci, S. (2017). Digital Innovations in Architectural Heritage Conservation: Emerging Research and Opportunities. IGI Global.

Calvano, M., Guadagnoli F., (2017). 3D reconstruction of the city of Amatrice. An "instant modelling" operation. Disegnarecon, 9(17).

Feriozzi, R., Meschini, A., Rossi, D. (2017). La Basilica in una scatola. Proposta per una wunderkammer contemporanea. Disegnarecon, 9(17).

Meschini, A., Rossi, D., Petrucci, E., \& Sicuranza, F. (2017). Expanded Cultural Heritage Representation: Digital Applications for Mixed-Reality Experiences. In Handbook of Research on Emerging Technologies for Digital Preservation and Information Modeling (pp. 256-287). IGI Global. 